\title{
CYCLE TIME REDUCTION STUDIES IN THREADING
}

\author{
K. PALAKSHA REDDY ${ }^{1}$, DEEPAK KUMAR ${ }^{2}$, R. VENKATRAMAN ${ }^{3} \& V$. VISHWESHVAR ${ }^{4}$ \\ ${ }^{1,2,4}$ School of Mechanical Engineering, SASTRA Deemed To Be University, Thanjavur, Tamilnadu, India \\ ${ }^{3}$ Shanmugha Precision Forgings, A Unit of SASTRA Deemed To Be University, Thanjavur, Tamilnadu, India
}

\begin{abstract}
Cycle time reduction is one of the critical aspects for achieving successful production of products. Prompt delivery, high quality of products have now become the significant factors for customer satisfaction. The various methods of programming in CNC systems ensure machine ability, but at the same time optimization and increase in productivity are to be enhanced. Various programming methods in manufacturing of threads were studied in this research work. The cycle times of three different work piece materials during the G76 threading cycle were noted. Then, we proposed G92 cycle of threading to reduce the cycle time. The new process enabled variable depth of cut, less number of passes resulting in cycle time and it is easy to use. The work was practically implemented on a CNC lathe machine and the data related to the experiments were recorded. This method was applied to 10 other work pieces, wherein it was noted that for all types of threads manufactured, a considerable amount of time is being saved and the productivity was increased marginally.
\end{abstract}

KEYWORDS: CNC Programming, Canned Cycles, Threading Cycle, G76 \& G92

Received: Jan 08, 2018; Accepted: Jan 30, 2018; Published: Feb 26, 2018; Paper Id.: IJMPERDAPR201816

\section{INTRODUCTION}

Product cycle time is the time interval taken by a manufacturer for complete development and production of a product. The time taken for this process is significant, because it reflects the ability of a company to reach market or to react to changes in customer demands and desires. Reduction in cycle time can improve efficiency and optimize profit potential. Optimal selection of production processes helps to reduce cycle time, which results in cost saving. This can be achieved by a thorough analysis of every step of the production process, rectifying inefficient steps and eliminating steps irrelevant to the process. Thus, there is a growing need for good quality, high process safety, minimal manufacturing cost, quick payback for $\mathrm{CNC}$ machines, balance between quality and cost at each stage of operation, shorter manufacturing times, reduced field failure of a product and process related controllable input variables at their optimum operating conditions.

Threading is a machining process used to produce a helical groove of a given shape and size, usually on a cylinder (Straight thread), or on a cone (tapered thread). The major purpose of threads is to connect two parts together without damage during joining and disjoining. Threading on CNC machines can do using G76 or G92 cycles. G76 thread cutting cycle is one example of canned cycle. Canned cycles or fixed cycles can automate operations such as drilling, boring, threading, pocketing, etc. Canned cycles allow an easier way to program a machine to produce a feature of a part [11].

\section{LITERATURE REVIEW}

Santoshkumar et al. [1] Have studied the effect of the implementation of lean manufacturing principles on 
reduction of cycle time of truck body assembly in an automobile industry. The take time for the assembly line was studied briefly and they have concluded that application of proper line balancing has resulted in an eloquent reduction in cycle time and increase in overall efficiency of the assembly line. Saran kumar reddy, et al. [2] have reported that reduction of cycle time in a bearing house assembly was achieved by adopting variation in production/process type, pre machining the components and also by implementing new tool. Also, the implementation of certain lean principles such as 5S, SMED and pull production system have effected in overall cycle time reduction of the component. They have further extended their conclusion suggesting variation in process parameters such as speed, feed, depth of cut, etc., will also result in cycle reduction of the component.

Venkatraman et al. [3] have studied the reduction of cycle time in a machining process using value stream mapping. It was reported that on employing lean manufacturing strategies in crankshaft manufacturing system, which aimed to eliminate the 8 non-value added wastes like over processing, over production, searching and waiting, unnecessary transportation and defects and errors from the manufacturing system and also enables product variability in the manufacturing cell. As a result, the manufacturing lead time was reduced by $40 \%$, defects were reduced, process capability was increased and response to the customer demand in small lots was accelerated. Young Hoon lee and Taeheon [4] Kim have focused on reduction in cycle time in semiconductor fabrication using balance control. The work discusses in ascertaining the correct WIP level for operations, against which balance status can be measured. Mathematical modelling of balance measurements were done for bottleneck scheduling and operations management of the fabrication line. Through computational experiments, performance was evaluated and the results showed that balance driven management helps in $33 \%$ more production in $21 \%$ lesser manufacturing cycle time than production driven management.

Ashwinkumar Arivoli et al. [5] have made a case study on reduction of cycle time using line balancing algorithm. The studies were conducted in an industry that manufactures air - oil separators for compressor and the study was restricted to bottle neck station. Various tools such as the Fishbone diagram, Pareto chart, Value Stream Mapping were used to check the adherence of current process with the takt time. With the help of line balancing algorithm using CAMSOAL software, $5 \%$ reduction in cycle time was achieved to meet the takt time at the bottle neck station. M. Klarin et al. [6] Have done a case study in a reduction of production cycle time by optimizing production and non-production components of time in the metalworking industry. Their works focused to survey and control the methodology of reducing the production cycle time of components, coupled with factor analysis into the factors of production and non-production components, ascertained by a modified method of current observations, and viewed as a process whose effectiveness was monitored using control charts. The empirical results provided an understanding on a number of managerial issues concerning investment decisions in product-specific cycle time improvements and reductions, together with process redesigns.

Sandeepmalik et al. [7] have studied the implementation of cycle time reduction technique in an industry which involved deep study on the processes happening throughout the industry, identification of different obstacles to implementation of cycle time reduction technique. They have categorized the obstacles as technical, business and cultural barrier and have investigated the effect of each on cycle time reduction. The results reported shows with proper study and application of appropriate techniques, cycle time reduction has resulted in increase in overall productivity. P C Chauhan et al. [8] have experimentally investigated the effect of surface roughness of blank diameter on dimensions external threads. The work had been carried out on thread rolling machine using HSS die and Sup 9A work piece. It was reported that the 
surface roughness affected the thread dimensions drastically and an improved surface finish led to increase in both nominal diameter and pitch circle diameter of the thread produced. Ajay Bangar et al. [9] have found that hardness, surface roughness and blank diameter had significant effect on dimensions of thread on external threading of threaded bolts manufactured by flat reciprocating die on different materials like mild steel, En-8, En-47. It was observed that the reduction of carbon content lead to increase in outer diameter of the thread and increase in surface roughness led to increase in the former. Further, the results were optimized by Taguchi technique and with the help of regression modelling the variation of outer diameter with aforementioned parameters had been modelled. Abu ali et al. [10] have explored the impact of product innovativeness and entry strategy in cycle time and initial market performance of thirty seven small manufacturing firms andresults indicate that these firms are able to achieve shorter cycle time by keeping the technical content of the product simple without any compromise in quality. They further emphasize that the break-even time is one of the crucial parameter that indicates market performance of a firm and the cycle time as a mediator between authoritative actions and market performance.

\section{EXPERIMENTAL METHODOLOGY}

The production process for 10 work pieces were studied in the Industry. G76 threading cycle was used for manufacturing of thread in all the 10 parts. The G76 threading cycle is a canned cycle that provides an ease in programming to produce thread in a product, it provides great flexibility and gives control over number of spring passes, depth of first cut, depth of finish cut, in feed angle and many more [11]. An alternate G92 threading cycle was proposed and implemented for manufacturing of thread in the 10 work pieces. G92 is a box type cycle in which depth of thread cut for each pass is given as input. Although G92 involves lengthy programming yet it allows control over number of passes in which the thread is to be produced and this attribute has been exploited to reduce the number of passes in which the thread is produced thus reducing the threading cycle time. The experiments were conducted on a CNC horizontal lathe with coated thread inserts. The photographs of the parts are shown in Figures 1, $2 \& 3$ and the grades of the materials being machined with their assigned part names are shown in Table 1.

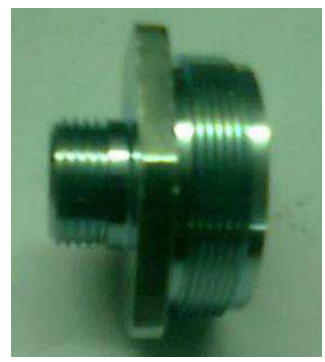

1. Adapter

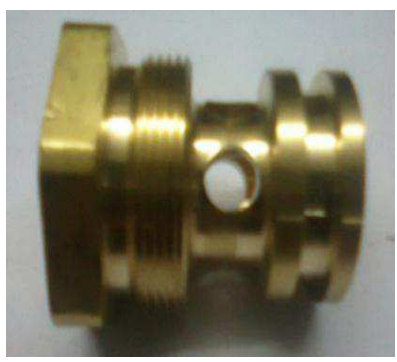

3. Seat

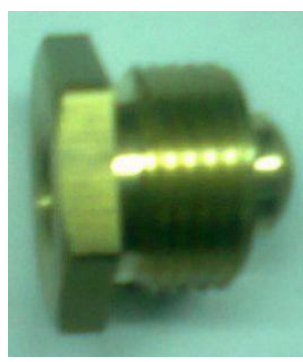

4. End cap

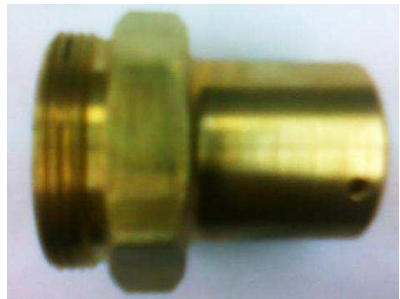

5. Cap end

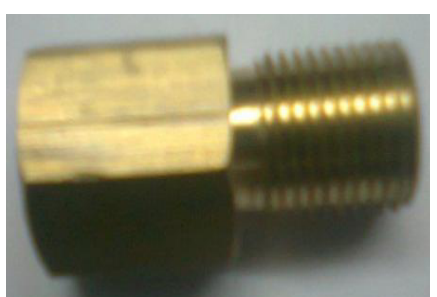

9. Stem bolt

Figure1: Photographs of Brass Work pieces 


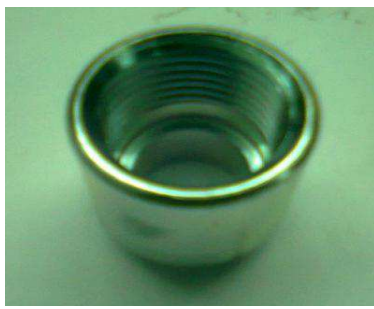

6. Conduit connector

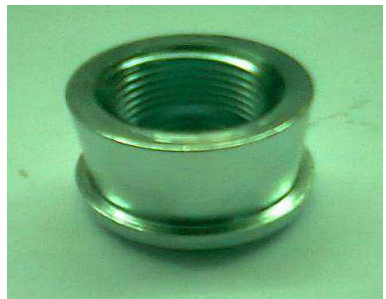

10. Connector

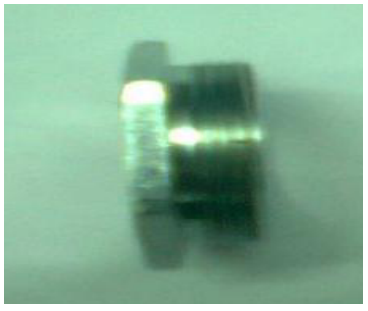

2. Bonnet-bar stock

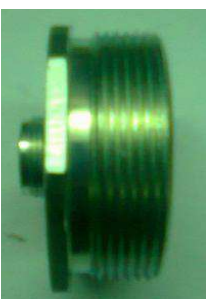

7. Bar stock bonnet

Figure 2: Photographs of Mild Steel Work pieces

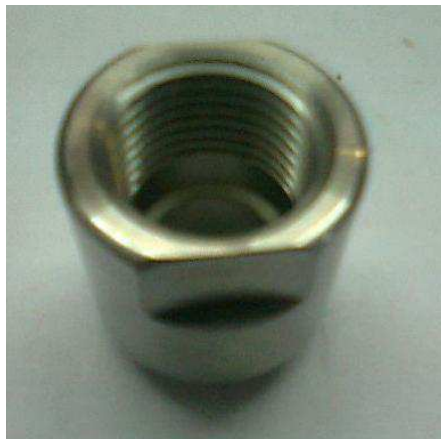

8. Connector

Figure 3: Photograph of SS Workpiece

Table 1: Workpiece Material, Thread Profile and Inserts

\begin{tabular}{|c|l|l|l|l|l|l|}
\hline \multirow{2}{*}{ No. } & \multirow{2}{*}{$\begin{array}{c}\text { Part } \\
\text { Name }\end{array}$} & \multicolumn{1}{|c|}{ Material } & \multirow{2}{*}{$\begin{array}{l}\text { Thread } \\
\text { Profile }\end{array}$} & \multicolumn{1}{|c|}{ Threading } & \multicolumn{2}{|c|}{ Brand } \\
\hline 1 & Adapter & Brass (IS 319 II) & Partial & 16 ERM AG-60 & SER 2525 K16 & Tagutech \\
\hline 2 & $\begin{array}{l}\text { Bonnet, } \\
\text { bar stock }\end{array}$ & MS (12 L 14) & Full & 3 ER-26 UN & SER 2020 M16 & Vartex \\
\hline 3 & Seat & Brass (IS 319 II) & Partial & 16 ERM AG-60 & SER 2525 K16 & Tagutech \\
\hline 4 & End cap & Brass (IS 319 II) & Full & 16 ERM -14 & SER 2525 K16 & ISCAR \\
\hline 5 & Cap end & Brass (IS 319 II) & Full & 3 ER-26 UN & SER 2020 M16 & Tagutech \\
\hline 6 & $\begin{array}{l}\text { Conduit } \\
\text { connector }\end{array}$ & MS (12 L 14) & Full & 16IRM 14 NPT & SIR S16-13 & Tagutech \\
\hline 7 & $\begin{array}{l}\text { Bar stock } \\
\text { bonnet }\end{array}$ & MS (12 L 15) & Full & 3ER 28 UN & SER 2525 K16 & Vartex \\
\hline 8 & Connector & SS (SS 316) & Full & 16IRM 14 NPT & SIR S16-13 & Tagutech \\
\hline 9 & Stem bolt & Brass (IS 319 II) & Full & 3ER 28 UN & SER 2525 M16 & Tagutech \\
\hline 10 & Connector & MS (1215) & Full & 16IRM 14 NPT & SIR S16-13 & Tagutech \\
\hline
\end{tabular}

Both the G76 and G92 programming methodologies were implemented in the production of thread in afore mentioned 10 parts, accordingly the data for the cycle time, number of passes and number of pieces per shift were noted both before and after the threading with G76 and G92 cycles. The G76 threading cycle method used in manufacturing of thread in the part No: 01, Part name: adapter, Material: Brass (IS319 II)) is programmed as follows:

\section{G76 P030055 Q50 R30}

G76 X36.474 Z -12.30 P812 Q150 F1.27

Where, 


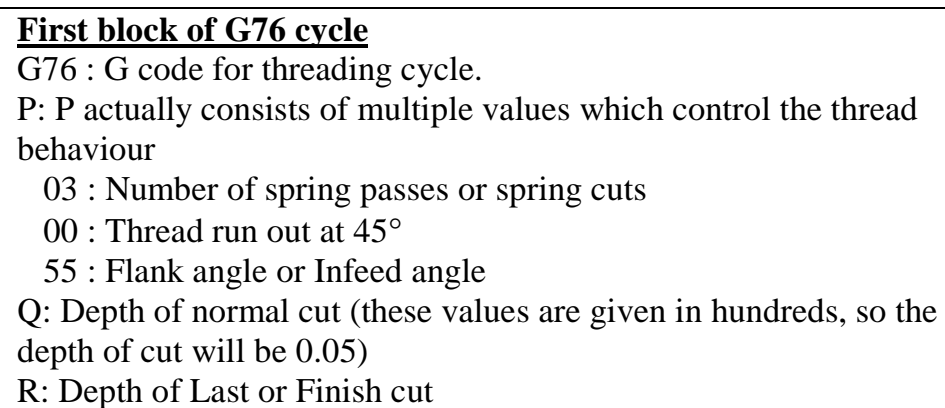

Second block of G76 cycle

G76: $\mathrm{G}$ code of the threading cycle

$\mathrm{X}$ : The end value in $\mathrm{X}$-axis

$\mathrm{Z}$ : The end value in $\mathrm{Z}$-axis

$P$ : Thread depth ( as radius value )

$\mathrm{Q}:$ Depth of first cut

F : Thread Pitch

Note: The final diameter ( $\mathrm{X}$ value in the second block of the G76 code), depth of last or finish cut and depth of normal cut are the important parameters to be specified and the number passes required to produce is decided by the program.

\begin{tabular}{|l|l|}
\hline G92 threading cycle: & \\
G92 Z-12.30 U0.0 F1.27 & X36.494 \\
X37.994 & X36.474 \\
X37.594 & Where, \\
X37.234 & Z- The end value in z-axis or the length of the thread. \\
X36.914 & F- Threading feed rate or Thread pitch \\
X36.794 & X-Current diameter of the thread pass \\
X36.674 & \\
X36.514 & \\
\hline
\end{tabular}

\section{RESULTS AND DISCUSSIONS}

The G92 threading cycle offers control over depth of cut in each pass of threading operation in this way it indirectly gives control over number of passes required to produce thread and enables the user to vary depth for each pass. The G92 programming method for the manufacturing of threads was practically implemented in the CNC turning lathe after successive trials. The tool was run and properly inspected throughout the experimental process. Accordingly, the data for the cycle time, number of passes and number of pieces per shift were noted for both G76 and G92 cycles as shown in Table 2.

Table 2: Experimental Data on Cycle Time Reduction in Threading

\begin{tabular}{|c|c|c|c|c|c|c|c|c|c|c|c|}
\hline \multirow{2}{*}{ No } & \multirow{2}{*}{$\begin{array}{l}\text { Quantity / } \\
\text { month }\end{array}$} & \multirow{2}{*}{ Part Name } & \multirow{2}{*}{ Material } & \multicolumn{3}{|c|}{ Cycle Time, sec } & \multicolumn{2}{|c|}{ No of Passes } & \multicolumn{2}{|c|}{$\begin{array}{c}\text { No of } \\
\text { Pieces/Shift }\end{array}$} & \multirow{2}{*}{$\begin{array}{c}\text { Cost Savings } \\
\text { per Month } \\
\text { (Rs.) }\end{array}$} \\
\hline & & & & G76 & $\begin{array}{l}\text { G9 } \\
2\end{array}$ & $\%$ reduction & G76 & G92 & G76 & G92 & \\
\hline 1 & 929 & Adapter & Brass & 42 & 26 & 38.1 & 16 & 10 & 117 & 124 & 743 \\
\hline 2 & 6891 & Bonnet, bar stock & MS & 29 & 16 & 44.8 & 11 & 6 & 361 & 420 & 4479 \\
\hline 3 & 1267 & Seat & Brass & 43 & 26 & 39.5 & 12 & 7 & 84 & 88 & 1077 \\
\hline 4 & 1111 & End cap & Brass & 90 & 58 & 35.6 & 18 & 11 & 87 & 95 & 1777 \\
\hline 5 & 1253 & Cap end & Brass & 29 & 18 & 37.9 & 11 & 5 & 192 & 204 & 689 \\
\hline 6 & 841 & Conduit connector & MS & 85 & 69 & 18.8 & 18 & 12 & 87 & 92 & 673 \\
\hline 7 & 646 & Bar stock bonnet & MS & 64 & 48 & 25.0 & 15 & 8 & 58 & 61 & 517 \\
\hline 8 & 110 & Connector & SS & 85 & 74 & 12.9 & 19 & 12 & 80 & 83 & 61 \\
\hline 9 & 124 & Stem bolt & Brass & 40 & 25 & 37.5 & 13 & 7 & 90 & 94 & 93 \\
\hline 10 & 197 & Connector & MS & 51 & 34 & 33.3 & 15 & 8 & 96 & 100 & 168 \\
\hline
\end{tabular}




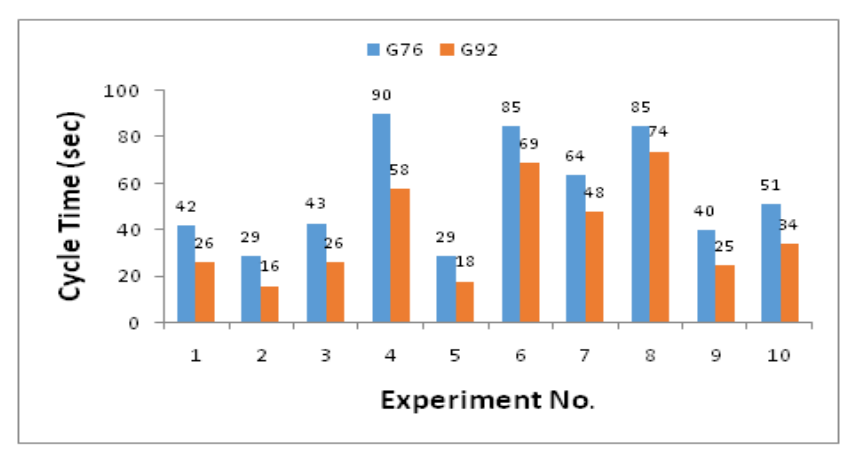

Figure 4: Comparison of the Cycle Time for 10 Parts when Manufactured by G76 and G92

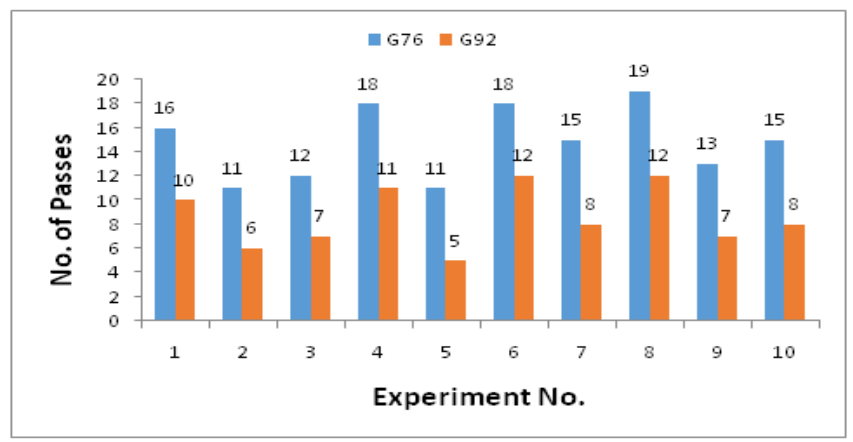

Figure 5: Comparison of the No. of Passes for 10 Parts when Manufactured By G76 and G92

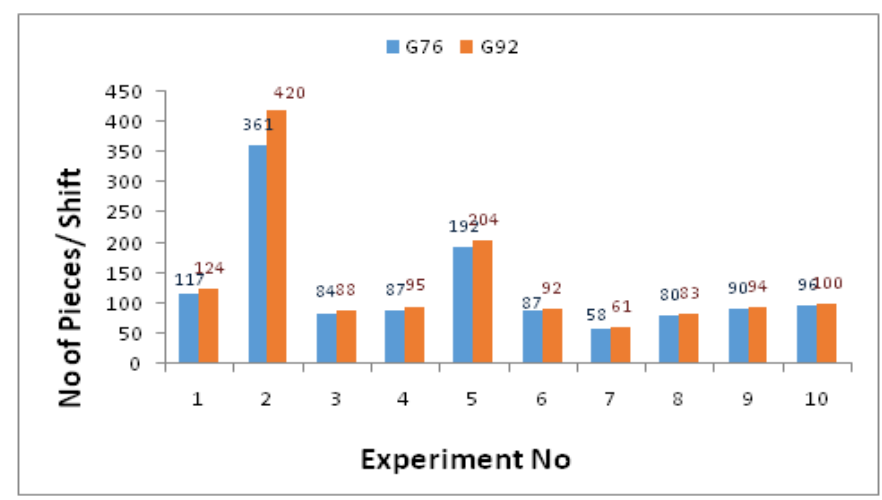

Figure 6: Comparison of the Number of Pieces per Shift for 10 Experiments when Produced by G76 and G92

Figures 4, 5 and 6 show comparison of cycle time, no. of passes and no. of pieces/shift for 10 parts made using G76 and G92 threading cycles. The cycle time has been reduced considerably in the G92 cycle than G76 cycle in all the 10 parts due to reduction in the number of passes as shown in Figure.5. In G92 threading cycle, each pass with different depth of cut can be programmed thereby the total depth of thread cut can be achieved in less number of passes than that required in G76 threading cycle by dividing the depth of the thread accordingly for each pass. Where as in the G76 cycle, the final diameter, depth of finish cut and total depth of thread cut need to be specified and the program calculates the number of passes to produce thread.

\section{CONCLUSIONS}

- The G92 threading cycle offers user to have control over the number of passes required by enabling the 
programmer to produce variable depth of cut in each pass.

- The G92 threading cycle implemented as an alternative to G76 threading cycle has resulted in a reduction in cycle time and the number of passes for manufacturing threads in components in all the 10 parts as shown in Table 2 , Figure.4 and Figure.5.

- The number of pieces manufactured per shift and cost savings per month has increased for all the 10 parts manufactured using G92 threading cycle than G76 threading cycle as shown in Table 2 and Figure. 6.

- The combined effect of reduction in cycle time, increase in the number of pieces produced per shift and cost saving has resulted in an increase in productivity for each part.

\section{REFERENCES}

1. S. Santhosh Kumar, M. Pradeep Kumar, Cycle Time Reduction of a Truck Body Assembly in an Automobile Industry by Lean Principles, In Procedia Materials Science, Volume 5, 2014, Pages 1853-1862, ISSN 2211-8128.

2. K. Saran Kumar Reddy, T. PanneerSelvam and R. Venkatraman, 2012. Cycle Time Reduction for Bearing House Assembly. Journal of Applied Sciences, 12: 992-998

3. K. Venkataraman, B. VijayaRamnath, V. Muthu Kumar, C. Elanchezhian, Application of Value Stream Mapping for Reduction of Cycle Time in a Machining Process, In Procedia Materials Science, Volume 6, 2014, Pages 1187-1196, ISSN:2211-8128.

4. Young Hoon Lee \& Taeheon Kim, Manufacturing cycle time reduction using balance control in the semiconductor fabrication line, Production Planning \& Control Vol. 13, Issue. 6, 2002, Pages 529-540.

5. AshwinkumarArivoli\&VigneshRavichandran, Reduction of Manufacturing Cycle Time using Line Balancing - A Case Study, International Journal of Innovative Research in Science, Engineering and Technology, Vol. 4, Issue 11, November 2015.

6. SpasojevićBrkić, V. et al., Reduction of production cycle time by optimising production and non-production components of time in the metalworking industry: A case study. S. Afr. J. Ind. Eng. 2016, vol.27, n.1, pp.178-191. ISSN 2224-7890.

7. Sandeep Malik, NishantPahwa, Vinod Malik, Implementation of Cycle Time Reduction Technique in Industry, International Journal of Manufacturing Science and Engineering, International Science Press, Vol. 2, No. 2, July-December 2011.

8. S. Chauhan, P\& C. Arora, K. Experimental study of effect of surface roughness of blank diameter on external threads. IJMTM. 17. 386-395, 2009.

9. Ajay Bangar, et al., 'Design Analysis of External threaded Bolts Manufactured by Flat Reciprocating Die with the help of Taguchi Optimization Technique', International journal of advanced scientific and technical research Issue 2 volume 6, December 2012

10. Ali, A., Krapfel, R. and LaBahn, D. (1995), Product Innovativeness and Entry Strategy: Impact on Cycle Time and Break-even Time. Journal of Product Innovation Management, 12: 54-69.

11. Peter Smid, 'CNC Programming Handbook', Third Edition, A Comprehensive Guide to Practical CNC Programming. 
